\title{
EFEITO DA ENZIMA FITASE NAS RAÇÕES DE FRANGOS DE CORTE, DURANTE AS FASES PRÉ-INICIAL E INICIAL ${ }^{1}$
}

\author{
Effect of phytase enzyme in broilers rations, during pre-starter and starter phases
}

\author{
Fernando Guilherme Perazzo Costa², Patrícia Araújo Brandão ${ }^{3}$, Jocelyn Santiago Brandão ${ }^{4}$, \\ José Humberto Vilar da Silva
}

\begin{abstract}
RESUMO
Foram criados 1.080 pintos de corte machos, no período de 1 a 7 e 8 a 21 dias de idade, para estudar os efeitos da fitase nas rações sobre o desempenho. Utilizaram-se duas rações experimentais para cada fase, sendo a primeira formulada por uma empresa integradora de frangos de corte (E-1) e a segunda sugerida pela empresa fornecedora da enzima (E-2). Os tratamentos foram: T1 e T4 - ração sem adição da enzima e T2 e T3 - ração com fitase. O delineamento experimental utilizado foi o inteiramente casualizado, num arranjo fatorial 2 x 2 (duas rações e dois níveis de enzima), com nove repetições e trinta aves por parcela. A enzima foi adicionada na quantidade de $100 \mathrm{~g} / \mathrm{t}$ de ração. Houve diferença significativa $(\mathrm{P}<0,01)$ entre tratamentos para ganho de peso e conversão alimentar para as fases pré-inicial e inicial, sendo os melhores resultados obtidos com a E-1 com adição de enzima, mostrando a importância da fitase em rações com frangos de corte quanto ao desempenho dos animais.
\end{abstract}

Termos para indexação: Avicultura, desempenho, enzima, nutrição animal.

\begin{abstract}
1.080 male broilers were used from 1 to 7 and 8 to 21 days of age to evaluate phytase diet supplementation in chicks performance. Two experimental rations were used each phase, whereas the first diet recommended by company broiler integrator (C-1) and the second suggested by furnished company enzyme (C-2). Treatments consisted in: T1 and T4 - ration without enzyme and T2 and T3 - ration with enzyme. A completely randomized design was used, in a 2 x 2 factorial model (two rations x two levels of enzyme) with nine replicates and 30 birds per unit. The enzyme was used in amount of $100 \mathrm{~g} /$ ton of ration. Statistically significant difference $(\mathrm{P}<0.01)$ was found between treatments to weight gain and feed:gain ratio to pre-starter and initial phases, where best results were obtained with $\mathrm{C}-1$ with enzyme addition, showing the importance of phytase in broiler chicks rations as to birds performance.
\end{abstract}

Index terms: Poultry, performance, enzyme, animal nutrition.

(Recebido em 11 de agosto de 2005 e aprovado em 28 de julho de 2006)

\section{INTRODUÇÃO}

Em virtude da alta velocidade de ganho de peso e precocidade dos frangos de corte, atualmente é essencial a utilização de produtos que permitam aos animais obterem um desempenho cada vez melhor.

$\mathrm{Na}$ área de nutrição avícola a utilização de enzimas tem contribuído para a melhoria da produtividade das aves. As aves não sintetizam ou produzem em quantidades suficientes certas enzimas endógenas, utilizadas para a digestão dos vários componentes químicos encontrados nos alimentos de origem vegetal ou para atuarem em alguns processos antinutricionais, como o fósforo fítico. Segundo Perney et al. (1993), o uso da enzima exógena fitase para monogástricos tem sido muito preconizado devido sua habilidade em hidrolisar o fósforo fítico que é pouco utilizado por esta classe de animais.
No Brasil, as rações para frangos de corte são formuladas principalmente à base de milho e farelo de soja, onde representam cerca de $90 \%$ da dieta, contribuindo substancialmente para satisfazer as necessidades em energia, proteínas, minerais e vitaminas de acordo com as tabelas e recomendações das empresas fornecedoras das linhagens existentes no mercado.

O uso de enzimas nas rações das aves e outros animais domésticos, melhora a digestibilidade e disponibilidade de certos nutrientes para os animais, principalmente o fósforo, nitrogênio, cálcio, cobre e zinco, diminuindo sua presença nas fezes e, conseqüentemente, o seu potencial de poluente do meio ambiente (REVISTA ALIMENTAÇÃO ANIMAL, 2002). A maior preocupação ocorre com o fósforo dos ingredientes vegetais, que por

\footnotetext{
${ }^{1}$ Parte da dissertação de Mestrado do segundo autor.

2Doutor, Centro de Ciências Agrárias/CCA - Universidade Federal da Paraíba/UFPB - Cx. P. 09 - 58397-000 - Areia, PB - fperazzo@cca.ufpb.br ${ }^{3}$ Doutora, Centro de Saúde e Tecnologia Rural/CSTR - Universidade Federal de Campina Grande/UFCG - Cx. P. 64, 58700-970 - Patos, PB patriciaaraujobrandao@bol.com.br

${ }^{4}$ Mestre, Centro de Saúde e Tecnologia Rural/CSTR - Universidade Federal de Campina Grande/UFCG - Cx. P. 64, 58700-970 - Patos, PB santiagobrandao@bol.com.br

${ }^{5}$ Doutor, Centro de Formação de Tecnólogos/CFT - Universidade Federal da Paraíba/UFPB - 58220-000 - Bananeiras, PB - jvilar@cft.ufpb.br
} 
estar ligado ao ácido fítico na forma de fitato é pouco disponível aos animais monogástricos, pois estes não dispõem em quantidades suficientes da enzima fitase para aproveitá-lo, onde somente cerca de um terço do fósforo total destes alimentos está disponível para aves. A lixiviação do fósforo a partir de excretas de aves e outros animais domésticos para a água de superfície e lençóis freáticos é um grave problema de poluição ambiental que pode ser minimizado com o uso de uma enzima fitase exógena.

Nas últimas décadas, várias pesquisas foram realizadas com a finalidade de reduzir período de abate dos frangos de corte. Em 1954, era preciso $4 \mathrm{~kg}$ de ração para a ave produzir $1 \mathrm{~kg}$ de carne no período de 80 dias. Hoje, $1 \mathrm{~kg}$ de carne é obtido com 25 dias e uma conversão de 1,6. Esse avanço é devido à relação entre o desempenho e a nutrição e também aos métodos econômicos favoráveis e a melhoria genética dos animais. Com a ajuda de bactérias e fungos, a tecnologia da fermentação tem produzido uma grande quantidade de enzimas que podem degradar várias formas de amido, açúcares, proteínas, fósforo e celulose para uma absorção mais rápida no trato digestivo.

Vários preparados enzimáticos têm sido utilizados para solucionar problemas digestivos, onde seu benefício terapêutico é muito reconhecido. Contudo, os novos avanços na biotecnologia propiciam a produção eficiente de algumas enzimas como fitase, b-glucanase e pentosanase (SEARS \& WALSH, 1993).

Segundo Kornegay (2001), a fitase pode muito bem ser considerada a enzima milagrosa dos anos 90, assim como a soja foi descrita como a lavoura milagrosa por produzir proteína vegetal de alta qualidade nos anos 40 . Esta é uma idéia facilmente compartilhada por quem se atém a ler os trabalhos publicados nos últimos 10 anos e que tratam da fitase e da sua aplicação na nutrição animal (DARI, 2004).Este trabalho foi realizado com o objetivo de analisar o efeito da enzima fitase nas rações de frangos de corte sobre o desempenho, nos períodos de 1 a 7 e 8 a 21 dias de idade.

\section{MATERIAL E MÉTODOS}

A pesquisa foi conduzida no Módulo de Avicultura do Departamento de Zootecnia do Centro de Ciências Agrárias da Universidade Federal da Paraíba, Campus II, Areia-PB.

Foram utilizados 1080 pintos de corte de um dia, machos, da linhagem Ross para a fase pré-inicial com peso médio inicial de $48 \mathrm{~g}$ vacinados no incubatório contra as doenças de Marek e posteriormente contra Newcastle e
Gumboro, aos doze dias de idade. Para a fase seguinte (inicial), as aves não foram as mesmas e apresentaram um peso médio de $174 \mathrm{~g}$, sendo criadas anteriormente com uma ração formulada de acordo com Rostagno (2000). Ao final de cada fase de criação, pesaram-se as aves e sobras de ração, para em seguida avaliar o desempenho (consumo de ração, ganho de peso e conversão alimentar) dos animais.

Foram utilizadas duas rações experimentais, sendo a primeira sugerida por uma empresa integradora de frangos de corte no Estado da Paraíba (E-1) e a segunda, formulada pela empresa fornecedora da enzima (E-2), cada uma delas sem e com adição da fitase e de acordo com as recomendações de Rostagno (2000).

A enzima fitase utilizada foi a Natuphos ${ }^{\circledR} 5000$, produto fabricado pela empresa BASF, obtida pela fermentação promovida por fungos do grupo Aspergillus niger, sendo um pó de cor amarelo pardo, facilmente miscível em água, que contém atividade de fitase mínima de 5000 FTU/g. Uma unidade de atividade de fitase (FTU) é definida pela quantidade de enzimas que libera 1 micromol de fósforo inorgânico em 1 minuto num substrato de sódiofitato a $37^{\circ} \mathrm{C}$ em $\mathrm{pH} 5,5$.

As rações foram formuladas à base de milho e de farelo de soja, mantendo-se isoenergéticas, isoprotéicas e isonutritivas, com $23 \%$ de $\mathrm{PB}$ e $2.930 \mathrm{kcal} / \mathrm{kg}$ de energia metabolizável (EM) na fase pré-inicial e $21 \%$ de PB e 3.050 $\mathrm{kcal} / \mathrm{kg}$ de EM na fase inicial da criação, conforme a Tabela 1. A enzima foi adicionada nas rações em substituição ao inerte.

$\mathrm{Na}$ fase pré-inicial (1 a 7 dias), os animais foram alojados em baterias metálicas tipo "brasília", com piso de tela coberto com papel e comedouro e bebedouro tipo calha. $\mathrm{O}$ aquecimento dos pintos foi feito usando um sistema elétrico, com uma lâmpada incandescente de $60 \mathrm{~W}$ por parcela, que permaneceu ligado até o $12^{\circ}$ dia de vida, sempre que necessário. Na fase inicial ( 8 a 21 dias), que teve a duração de 14 dias, os animais foram transferidos para os boxes com dimensões de 1,40 x 1,90 m, com piso de cimento e cobertos com cama de bagaço de cana. A partir deste período, foram utilizados comedouros tubulares e bebedouros pendulares, além de água e ração à vontade.

As médias de temperatura registradas no galpão durante o período experimental, utilizando termômetros de máxima e mínima foram de 29,4 e $26,7^{\circ} \mathrm{C}$, respectivamente.

$\mathrm{O}$ delineamento experimental utilizado foi o inteiramente casualizado (GOMES, 1990) num esquema fatorial 2 x 2 (duas rações x dois níveis de enzima), com nove repetições e 30 aves por unidade experimental, totalizando 1080 aves. 
TABELA 1 - Composição percentual e química calculada das rações experimentais, nos períodos pré-inicial e inicial de criação.

\begin{tabular}{|c|c|c|c|c|}
\hline \multirow[t]{3}{*}{ Ingredientes } & \multicolumn{4}{|c|}{ Rações com enzima (\%) } \\
\hline & \multicolumn{2}{|c|}{ Pré-inicial } & \multicolumn{2}{|c|}{ Inicial } \\
\hline & (E1) & (E2) & (E1) & (E2) \\
\hline Milho & 56,26 & 57,79 & 60,34 & 61,94 \\
\hline Soja Extrusada & 8,60 & 3,30 & 14,50 & 9,10 \\
\hline Farelo de Soja (45\%) & 28,60 & 33,70 & 18,90 & 24,00 \\
\hline Farinha de carne e ossos & 5,50 & 3,80 & 5,00 & 3,30 \\
\hline Calcário calcítico & 0,00 & 0,40 & 0,25 & 0,65 \\
\hline Sal & 0,45 & 0,44 & 0,40 & 0,41 \\
\hline DL - Metionina (99\%) & 0,28 & 0,27 & 0,26 & 0,26 \\
\hline L-Lisina $(78,4 \%)$ & 0,08 & 0,07 & 0,12 & 0,11 \\
\hline Suplemento Vitamínico ${ }^{1}$ & 0,05 & 0,05 & 0,03 & 0,03 \\
\hline Suplemento Mineral ${ }^{2}$ & 0,04 & 0,04 & 0,05 & 0,05 \\
\hline Cloreto de Colina $(70 \%)$ & 0,05 & 0,05 & 0,05 & 0,05 \\
\hline Avatec (Lasalocida de sódio) ${ }^{3}$ & 0,05 & 0,05 & 0,05 & 0,05 \\
\hline Enradin (Enramicina) ${ }^{3}$ & 0,01 & 0,01 & 0,01 & 0,01 \\
\hline Colistina (Bacitracina de zinco) ${ }^{3}$ & 0,01 & 0,01 & 0,01 & 0,01 \\
\hline Banox $^{4}$ & 0,01 & 0,01 & 0,01 & 0,01 \\
\hline Natuphos $^{5}$ & 0,01 & 0,01 & 0,01 & 0,01 \\
\hline Tot a l & 100,00 & 100,00 & 100,00 & 100,00 \\
\hline \multicolumn{5}{|l|}{ Valores calculados } \\
\hline Proteína Bruta (\%) & 23,00 & 23,00 & 21,00 & 21,00 \\
\hline Energia Metabolizável (kcal/kg) & 2.930 & 2.930 & 3.050 & 3.050 \\
\hline Lisina total $(\%)$ & 1,32 & 1,32 & 1,22 & 1,22 \\
\hline Metionina+Cistina (\%) & 1,00 & 1,00 & 0,95 & 0,95 \\
\hline Fósforo Disponível (\%) & 0,50 & 0,50 & 0,46 & 0,46 \\
\hline Cálcio $(\%)$ & 1,00 & 1,00 & 1,00 & 1,00 \\
\hline
\end{tabular}

${ }^{1}$ Suplemento Vitamínico.

${ }^{2}$ Suplemento Mineral.

${ }^{3}$ Promotor de crescimento.

${ }^{4}$ Antioxidante.

${ }^{5}$ Nome comercial da enzima fitase (BASF).

Níveis de Suplementação de Vitaminas, Minerais e Aditivos (quantidade por kg/ração): Vit. A, 10.000UI; Vit.D 3 2.000UI; Vit. E, 30 UI; Vit. B, 2 mg; Vit. B 3 mg; Ac. Pantotênico, 12 mg; Biotina, 0,1 g; Vit. K 3 mg; Ácido fólico, 1 mg; Ácido nicotínico, $50 \mathrm{mg}$; Coxistac 12 (Salinomicina 12\%), $66 \mathrm{mg} ; 15 \mathrm{mg}$, cloreto de Colina (60\%), $6 \mathrm{mg}$; BHT, $1 \mathrm{mg}$; Vit. B 0,015 mg, Selênio, 0,25 mg, Manganês, 106 mg; Ferro, 100 mg; Cobre, 20 mg; Cobalto, 2 mg; Iodo, 2 mg e Excipiente q.s.p.1.000g.

As análises estatísticas das características foram realizadas utilizando-se o programa SAEG 8.0, desenvolvido pela UFV (1999). Na comparação das médias dos tratamentos, usou-se o teste F, ao nível de $5 \%$ de probabilidade.

No final do período de criação foram avaliados mortalidade, consumo de ração, ganho de peso e conversão alimentar.

\section{RESULTADOS E DISCUSSÃO}

\section{Fase pré-inicial (1 a 7 dias de idade)}

A mortalidade durante esta fase foi de $0,6 \%$ e as médias de consumo de ração (CR), ganho de peso (GP) e conversão alimentar (CA) são mostradas na Tabela 2 . 
TABELA 2 - Efeitos dos níveis da fitase Natuphos ${ }^{\circledR} 5000$ sobre o desempenho de frangos de corte Ross, machos, no período de 1 a 7 dias de idade.

\begin{tabular}{cccccc}
\hline Tratamentos & Origem & $\begin{array}{c}\text { Enzima } \\
(\mathbf{g} / \mathbf{t})\end{array}$ & $\begin{array}{c}\text { Consumo de } \\
\text { ração (kg/ave) }\end{array}$ & $\begin{array}{c}\text { Ganho de peso } \\
\text { (kg/ave) }\end{array}$ & $\begin{array}{c}\text { Conversão } \\
\text { alimentar }\end{array}$ \\
\hline 1 & Empresa 1 & 0 & $0,142 \mathrm{a}$ & $0,176 \mathrm{ab}$ & $0,806 \mathrm{ab}$ \\
2 & Empresa 1 & 100 & $0,141 \mathrm{a}$ & $0,178 \mathrm{a}$ & $0,791 \mathrm{~b}$ \\
3 & Empresa 2 & 100 & $0,145 \mathrm{a}$ & $0,177 \mathrm{a}$ & $0,820 \mathrm{a}$ \\
4 & Empresa 2 & 0 & $0,140 \mathrm{a}$ & $0,170 \mathrm{~b}$ & $0,826 \mathrm{a}$ \\
\hline Média & - & - & 0,141 & 0,175 & 0,810 \\
\hline CV & - & - & 2,75 & 2,64 & 2,67
\end{tabular}

Médias seguidas de letras distintas, dentro de cada coluna, diferem estatisticamente pelo Teste de Tukey $(\mathrm{P}<0,05)$.

Pelos resultados obtidos observou-se que houve diferença significativa $(\mathrm{P}<0,01)$ entre tratamentos quanto aos parâmetros ganho de peso e conversão alimentar.

Para ganho de peso (GP), as aves que consumiram as duas rações que continham a enzima (T2 e T3) apresentaram um peso maior $(\mathrm{P}<0,01)$ que os tratamentos sem adição de enzima (T1 e T4), proporcionando um aumento de $7 \mathrm{~g}(4,1 \%)$ e $2 \mathrm{~g}(1,1 \%)$ para as empresas 2 e 1 , respectivamente.

Este aumento no ganho de peso dos animais pode ter ocorrido pela diminuição da viscosidade intestinal das aves, melhorando a digestão e absorção dos nutrientes no trato digestivo destes animais. Estes resultados estão de acordo com os encontrados por Broz et al. (1994), Conte et al. (2000), Kersey et al. (1998), Namkung \& Leeson (1999), Perney et al. (1993), Pizzolante et al. (2000), Ravindran et al. (1999) e Sebastian et al. (1996). Segundo Tejedor et al. (2001), o aumento no ganho de peso ocasionado pela adição da enzima fitase pode ser explicado provavelmente pelo incremento na digestibilidade ileal da proteína bruta, do cálcio e do fósforo. Por outro lado, Bonato et al. (2001), Biehl \& Baker (1997), McKnight (1999) e Sebastian et al. (1996), não observaram efeito da adição da fitase neste parâmetro pesquisado.

Em relação à conversão alimentar $(\mathrm{CA})$, a empresa E-1 apresentou melhores resultados em comparação a empresa fornecedora da enzima (E-2), onde a fitase diferenciou-se $(\mathrm{P}<0,01)$ dos tratamentos sem enzima. A molécula de ácido fítico tem a capacidade de se ligar à proteína, em meios ácidos, alcalinos e neutro (ANDERSON, 1985, citado por SEBASTIAN et al., 1997), e reduzir a atividade da pepsina, tripsina e a amilase (SEBASTIAN et al., 1998). Espera-se melhorar o aproveitamento de proteína e de aminoácidos, por meio da quebra destes complexos nutritivos, pela utilização de fitase microbiana nas dietas.
Resultados semelhantes foram obtidos por Fernandes et al. (2003), em que a fitase adicionada na quantidade de 500FTU/kg foi capaz de disponibilizar fósforo fítico, proteína, aminoácidos e energia, dentro da equivalência nutricional proposta em rações de frangos de corte formuladas com milho e sorgo.

Segundo a Revista Alimentação Animal (2002), este resultado pode ser atribuído, ao fato de que a adição da enzima fitase nas rações das aves reduz a excreção de fósforo nas fezes e aumenta a disponibilidade de outros nutrientes, tais como os minerais (cálcio, zinco e cobre), proteínas, aminoácidos e energia, diminuindo desta maneira as excreções e melhorando conseqüentemente o desempenho desses animais.

A adição da enzima não afetou o consumo de ração $(\mathrm{P}>0,05)$. Estes resultados estão semelhantes aos de Bonato et al. (2001), Broz et al. (1994), Perney et al. (1993), Ravindran et al. (1999), Sebastian et al. (1996) e Tejedor et al. (2001), mas contrários a Conte et al. (2001), quando observaram um aumento no consumo de ração a partir do momento que a fitase foi adicionada às rações.

\section{Fase inicial (8 a 21 dias de idade)}

A mortalidade durante esta fase de criação foi de $1,02 \%$, sem efeito significativo $(\mathrm{P}>0,05)$ entre os tratamentos.

Os resultados da Tabela 3 mostram efeito significativo $(\mathrm{P}<0,05)$ para consumo de ração, onde o tratamento da E-2 com enzima proporcionou uma redução de $54 \mathrm{~g}(5,1 \%)$ em relação à ração sem enzima. Pizzolante et al. (2000) concordam com estes dados, mas Bonato et al. (2001), Sebastian et al. (1996), Tejedor et al. (2001) e Yi et al. (1996) observaram aumento no consumo de ração quando adicionaram fitase nas rações dos frangos de corte. 
TABELA 3 - Efeitos dos níveis da fitase Natuphos ${ }^{\circledR} 5000$ sobre o desempenho de frangos de corte Ross, machos, no período de 8 a 21 dias de idade.

\begin{tabular}{cccccc}
\hline Tratamentos & Origem & $\begin{array}{c}\text { Enzima } \\
(\mathbf{g} / \mathbf{t})\end{array}$ & $\begin{array}{c}\text { Consumo de } \\
\text { ração (kg/ave) }\end{array}$ & $\begin{array}{c}\text { Ganho de peso } \\
\text { (kg/ave) }\end{array}$ & $\begin{array}{c}\text { Conversão } \\
\text { alimentar }\end{array}$ \\
\hline 1 & Empresa 1 & 0 & $1,001 \mathrm{~b}$ & $0,690 \mathrm{a}$ & $1,451 \mathrm{~b}$ \\
2 & Empresa 1 & 100 & $1,027 \mathrm{ab}$ & $0,703 \mathrm{a}$ & $1,460 \mathrm{~b}$ \\
3 & Empresa 2 & 100 & $1,003 \mathrm{~b}$ & $0,672 \mathrm{~b}$ & $1,493 \mathrm{~b}$ \\
4 & Empresa 2 & 0 & $1,057 \mathrm{a}$ & $0,660 \mathrm{~b}$ & $1,601 \mathrm{a}$ \\
\hline Média & - & - & 1,022 & 0,681 & 1,501 \\
\hline CV & - & - & 3,85 & 1,771 & 3,84 \\
\hline
\end{tabular}

Médias seguidas de letras distintas, dentro de cada coluna, diferem estatisticamente pelo Teste de Tukey $(\mathrm{P}<0,05)$.

O aumento no ganho de peso dos animais foi maior para o tratamento 2 (com enzima) da E-1, diferenciando-se da E-2 com e sem enzima, no qual demonstra o efeito da fitase nas rações da referida empresa integradora de frangos de corte. Estes resultados são contrários aos de Biehl \& Baker (1997), Bonato et al. (2001) e McKnight (1999).

A adição da enzima no tratamento 2 (E-1) melhorou em $8,81 \%(141 \mathrm{~g})$ a conversão alimentar $(\mathrm{P}<0,001)$ em relação ao tratamento 4 (E-2), mostrando mais uma vez resultados superiores em relação à empresa fornecedora da enzima, onde esta diferença deva ser devido a melhor utilização dos ingredientes das rações. Os resultados estão coerentes com os encontrados por Conte et al. (2000), Ledoux et al. (1998), Tejedor et al. (2001) e Zhang et al. (1998).

\section{CONCLUSÃO}

A adição da enzima fitase nas rações dos frangos de corte nas fases pré-inicial e inicial apresentaram resultados superiores para desempenho em relação as rações sem enzima.

\section{AGRADECIMENTOS}

Agradecemos às empresas BASF S/A pela doação da enzima pesquisada e a GUARAVES - Guarabira Aves Ltda, pela integração e parceria com o Centro de Ciências Agrárias.

\section{REFERÊNCIAS BIBLIOGRÁFICAS}

BIEHL, R. R.; BAKER, D. H. Microbial phytase improves amino acid utilization in young chicks fed diets based $o$. soybean meal but not it diets based on peanut meal. Poultry Science, London, v. 76, p. 335-360, 1997.
BONATO, E. L.; ZANELLA, I.; ROSA, A. P. Efeito da adição de enzimas em dietas com níveis crescentes de farelo de arroz integral sobre o desempenho de frangos de corte. In: CONFERÊNCIA APINCO 2001 DE CIÊNCIA E TECNOLOGIA AVÍCOLAS, 2001, Campinas. Anais... Campinas: FACTA, 2001. p. 32.

BROZ, J.; OLDALE, P.; PERRINVOLTZ, A. H. Effects of supplemental phytase on performance and phosphorus diet without addition of inorganic phosphates. British Poultry Science, London, v. 35, p. 273-280, 1994.

CONTE, A. J.; TEIXEIRA, A. S.; SCHOULTEN, N. A. Efeito da fitase e xilanase em dietas com $15 \%$ de farelo de arroz, sobre o desempenho de frangos de corte aos 21 dias de idade. In: CONFERÊNCIAAPINCO 2001 DE CIÊNCIA E TECNOLOGIA AVÍCOLAS, 2001, Campinas. Anais... Campinas: FACTA, 2001. p. 26.

DARI, R. L. A utilização da fitase na alimentação de aves. In: CONFERÊNCIA APINCO 2004 DE CIÊNCIA E TECNOLOGIAAVÍCOLAS, 2004, Santos. Anais... Santos: FACTA, 2004. p. 127.

GOMES, F. P. Curso de estatística experimental. 13. ed. Piracicaba: Nobel, 1990. 468 p.

KERSEY, I. H.; SALEII, L. A.; ST1LBORN, I. L. L. Effect of dietary phosphorous level high available phosphorus corn and microbial phytase on performance and fecal phosphorus content: 1 . broiler grown 1 to $21 \mathrm{~d}$ in battery pens. Poultry Science, London, v. 77, n. 71, 1998. Supplement 1 . 
LEDOUX, D. R.; BROOMHEAD, J. N.; FIRMAN, J. D. Efficacy of phytassed, a phytase containing transgenic canola, to improve phytate phosphorus utilization from cornsoybean meal diets fed turkey poults from day 1 to 35 . Poultry Science, London, v. 77, n. 54, 1998. Supplement 1.

McKNIGHT, W. F. The impact of phytase and high available phosphorus corn on broiler performance and phosphorus excretion. In: PROCEEDINGS OF THE BASF TECHNICAL SYMPOSIUM, 1999, Atlanta. Anais... Atlanta: BASF, 1999. Seção 6, p. 57-66.

NAMKUNG, H.; LEESON, S. Effect of phytase enzyme on dietary nitrogen-corrected apparent metabolizable energy and ileal digestibility of nitrogen and amino acids in broiler checks. Poultry Science, London, v. 78, p. 13171319, 1999.

PERNEY, K. M.; CANTOR, A. H.; STRAW, M. L. The effect of dietary phytase on growth performance and phosphorus utilization of broiler chicks. Poultry Science, London, v. 72, n. 11, p. 2106-2114, 1993.

PIZZOLANTE, C. C.; TEIXEIRA, A. S.; SANTOS, C. D. Utilização da fitase na alimentação de frangos de corte: desempenho. In: CONFERÊNCIA APINCO 2000 DE CIÊNCIA ETECNOLOGIAAVÍCOLAS, 2000, Campinas. Anais... Campinas: FACTA, 2000.p. 45.

RAVINDRAN, V.; CABAHUG, S.; RAVINDRAN, O.; BRYDEN, L. Influence of microbial phytase on aparent ileal amino acid digestibility of feedstuffs for broiler. Poultry Science, London, v. 78, p. 699-706, 1999.

REVISTA ALIMENTAÇÃO ANIMAL. Uso de enzimas em rações. Disponível em: <http://bichoonline.com.br/artigos/ aa0041.htm>. Acesso em: 25 fev. 2002.

ROSTAGNO, H. S. Tabelas Brasileiras para aves e suínos: composição de alimentos e exigências nutricionais. Viçosa: UFV, 2000. 141 p.
SEARS, A.; WALSH, G. Industrial enzyme applications: using these concepts to match animal, enzyme and substrate. In: ASIA PACIFIC LECTURE TOUR, 1993. Anais... [S.1.]: ALLTECH, 1993. p. 89-110.

SEBASTIAN, S.; TOUCHBURN, S. P.; CHAVEZ, E. R. Efficacy of supplemental microbial phytase at different dietary calcium levels on growth performance and mineral utilization on broiler chickens. Poultry Science, London, v. 75, p. 1516- 1522, 1996.

SEBASTIAN, S.; TOUCHBURN, S. P.; CHAVEZ, E. R. Apparent digestibility of protein and amino acids in broiler chickens fed a corn-soybean diet supplemented with microbial phytase. Poultry Science, London, v. 76, p. 17601769, 1997.

SEBASTIAN, S.; TOUCHBURN, S. P.; CHAVEZ, E. R. Implications of phytic acid and supplemental microbial phytase in poultry nutrition: a review. Word's Poultry Science, London, v. 54, p. 27-47, 1998.

TEJEDOR, A. A.; ALBINO, L. F. T.; ROSTAGNO, H. S. Efeito da adição da enzima fitase sobre o desempenho e a digestibilidade ileal de nutrientes. Revista Brasileira de Zootecnia, Viçosa, v. 30, n. 3, p. 802-808, 2001.

UNIVERSIDADE FEDERAL DE VIÇOSA. SAEG 8.0 Sistema de Análises Estatísticas e Genéticas. Versão 8.0. Viçosa, 1999. 69 p.

YI, Z.; KORNEGAY, E. T.; DENBOW, D. M. Effect of microbial phytase on nitrogen and amino acid digestibility and nitrogen retention of turkey poults fed corn-soybean diets. Poultry Science, London, v. 75, p. 979-990, 1996.

ZHANG, Z. B.; KORNEGAY, E. T.; DENBOW, D. M. Comparison of genetically engineered microbial and plant phytase for young broilers. Poultry Science, London, v. 77, n. 71, 1998. Supplement 1. 